\title{
ELOGIO DEL PROF. JUAN JIMÉNEZ COLLADO
}

\author{
Francisco González de Posada \\ Académico de Número de la Real Academia Nacional de Medicina de España - Arquitectura e Ingeniería Sanitarias
}

1. Debo comenzar manifestando en primer lugar mi completa solidaridad con las magníficas y bellas palabras necrológicas de nuestro compañero, el eminente Dr. D. Pedro Guillén, discípulo entrañable, respetuoso y entregado a la vida y al recuerdo de su maestro, profesor Juan Jiménez Collado. ¡Excelente laudatio del colaborador y amigo dado a glosar el legado excepcional del académico que se nos ha ido, pendiente de él hasta el último momento de su vida, dedicándole una atención continuada, exquisita, de generosa y encomiable humanidad! Sí, excelente Discurso de despedida. ¿Puede decirse algo más? Prácticamente nada, dada su complitud y el cariño expresado en el recuerdo, ofreciendo lo pormenorizado y lo enaltecido, lo intelectivo y lo sensitivo, la verdad y el amor. Así con el Profesor Guillén me uno con sus palabras al "reconocimiento de grandezas y ejemplaridad gozosa y en muestra de gratitud", expresión clave en este recuerdo póstumo.

No tendría nada que decir, pero siento la necesidad, en cumplimiento del deber de gratitud y de difundir el legado del maestro, de la obligación de participar en esta memoria académica de nuestro compañero. Serán unas desperdigadas palabras de mi relación personal con él y una breve glosa de sus postreras actuaciones y de su legado vital primordial.

2. Mi contacto con la Anatomía en tanto que disciplina científica médica tuvo lugar a partir del encuentro con el Profesor Pedro Gómez Bosque desde mi estancia en Santander. A finales de los años 70 en la Facultad de Medicina de Cantabria, entonces con un exiguo número de catedráticos, existían, creo recordar, nada menos que tres catedráticos precisamente de Anatomía, todos ellos provenientes de Valladolid discípulos de Gómez Bosque. De esa universidad castellana dependían las primeras facultades de la Universidad de Santander, después de Cantabria durante mi rectorado. Hombre enormemente culto, íntegro y de humildad extrema, Gómez Bosque representaba, aunque fuera reducida, una escuela de Anatomía con su particularidad. Con ocasión de la sugerencia que nos hacía el profesor Luis Bru y con él Amador Schüller conocimos al doctor Juan Jiménez Collado, miembro relevante de la prestigiosa escuela creada por Francisco Orts Llorca. Gómez Bosque y Jiménez Collado pertenecían a distintas escuelas universitarias, poseían diferentes creencias y asumieron diversos compromisos, en los dos ejemplos, claros y firmes. Confieso que aprendí mucho de ambas escuelas y de ambos maestros. Las visiones prioritariamente antropológicas y filosóficas del primero y las embriológicas y católicas del segundo me aproximaban, cultivaban y animaban al conocimiento del ser humano desde perspectivas científicas y éticas, claramente complementarias y mutuamente enriquecedoras.

3. Juan Jiménez Collado, natural de San Roque, provincia de Cádiz, se hizo pronto, por motivos de estudio, gaditano en y de la capital. Mucho hablamos de nuestra común ciudad de Cádiz. Sus recuerdos de la Facultad gaditana, donde estudió la carrera, obteniendo el premio extraordinario, hizo el doctorado con análogo resultado y dio sus primeros pasos como profesor, supusieron quince años desde la juventud a la madurez.

Se integró en la cátedra de Anatomía regentada por Antonio López Rodríguez, discípulo y sucesor de Orts Llorca. Paralelamente a la cátedra, colaboraba con el maestro en una clínica de cirugía que disfrutaron primero en la calle Ancha y después en la plaza de Mina. ¡Cuántas veces me recordó su quehacer como cirujano allí con mi compañero de colegio, posterior catedrático de Anatomía en Cádiz, Juan Antonio Copano Abad! No era frecuente, al margen de la referencia Cádiz, que divulgara su quehacer profesional como cirujano. Esta faceta de su vida la coronaría formalmente con la obtención del título de 'Especialista en Cirugía General' del Ministerio de Educación y Ciencia en 1980.

Con su cariño a Cádiz, me recuerdan mis compañeros de Colegio que cursaron medicina, integrado en la 'escuela de Orts Llorca' de la que formaba parte López Rodríguez, se aficionó necesariamente y se entregó después a la tarea de la construcción de una enorme embrioteca 'personal' que continuaría en Madrid y tenía a gala incrementar y conservar con la lógica preocupación por su futuro. Junto a la embrioteca, según recuperan los colaboradores en su memoria, se había encariñado con una grande y antigua mesa de disección de mármol objeto que también era motivo de su frecuente recuerdo.

Poseía una casa en Cádiz en la glorieta Ingeniero La Cierva, en el centro de la playa de la Victoria, donde residía en sus veranos en la ciudad, pero, como nos ha recordado el Prof. Guillén, no pudo disfrutar de la Tacita de Plata en los veinte últimos años. ¡Cómo agradecía la recepción de mariscos del famoso restaurante Romerijo del Puerto de Santa María! Con ellos recibía a Cádiz 
4. Mi ingreso en la Real Academia Nacional de Medicina de España constituyó para mí el mayor honor recibido, siendo así que nunca he considerado tener los menores méritos para ello. Tampoco hice mucho en su logro. Fue el profesor Jiménez Collado, desde nuestro saludo en la casa de D. Luis Bru, académico tan querido en esta Real Academia, quien se entregó con una extrema generosidad y una gran eficacia para lograr mi ingreso que, como he expresado en diferentes ocasiones, modificó mi trayectoria universitaria con un notable impulso que significó el inicio de una nueva fase determinada por vuestra acogida en esta institución. A él se lo debo, entregado a la difícil tarea de la defensa de un candidato desconocido y externo.

Sea así, de nuevo, mi reconocimiento y gratitud. A él dediqué mi reciente tesis doctoral en Medicina, en abrazo de entrega de un modesto legado a esta Real Institución. Más, mucho más, que estima y aprecio, gratitud inmensa por su extrema generosidad. Gratitud y fidelidad.

5. El acceso de Jiménez Collado a la Secretaría de la Academia hizo que se identificara con ella de manera sorprendente. ¡Qué entrega! y ¡qué eficacia! Independientemente de los criterios que pudiéramos tener unos u otros. ¡Cuánto empeño puso durante su mandato! Sin duda como había dedicado en tantas ocasiones precedentes en tantos otros lugares. Paralelamente ocupó la vicepresidencia del Instituto de España, cuando éste lo era con funciones relevantes y organización autónoma supraacadémica, durante la presidencia de Salustiano del Campo. En este período de intensa actividad académica deseo recuperar para nuestra memoria dos aconteceres. Uno, su empeño en la institucionalización del Premio Nacional de Cirugía 'Pedro Virgili' que habíamos propuesto con el patrocinio del Ayuntamiento de Cádiz; Cirugía y Cádiz, dos sustantivos relevantes en su vida, y en esta tesitura, de nuevo juntos, pero en perspectiva nacional y desde la capital del Estado. Y otro, el importante paso dado para la conversión de la Academia creada en Santander por el Dr. Francisco Vázquez de Quevedo como 'Real', de Medicina y de Cantabria, academia asociada al Instituto de España.

6. El año 2001 tuve el honor de presentarlo como candidato a la Medalla de Honor al Fomento de la Invención propuesta que se aceptó. ¡Qué alegría le produjo la recepción de la medalla en el salón de plenos del Consejo Superior de Investigaciones Científicas!

7. Juan Jiménez Collado fue un hombre de fe. La basaba en pocos principios, pero era de fe firme en ellos, tanto en los de ámbito religioso como en los de ámbitos inmanentes, referidos a la política y a la sociedad. Pocos, pero claros, con firmeza a veces no exenta de osadía y valentía en algunos de sus planteamientos. Firmeza en la fe católica, y en sí mismo, como mostró en las dificultades que le planteó la vida.

8. Hemos oído en el brillante discurso del Prof. Guillén continuas referencias a las contribuciones del Dr. Jiménez Collado a la Embrio- logía, a sus numerosos estudios sobre embriones humanos, al Instituto de Embriología que fundó, ... a su profundo conocimiento científico de los instantes primigenios de los seres humanos, y en particular su referencia al memorable Discurso Inaugural del Curso Académico 2011, acontecimiento que podemos considerar 'histórico' en esta Real Academia, en defensa de la vida, basado en su conocimiento científico del embrión humano, originado en el instante de la concepción al fecundar un espermatozoide a un ovocito.

El acontecimiento de la fecundación o singamia supone e implica la emergencia de un nuevo ser humano en el que se desencadenará una sucesión de procesos, frutos de la dinamicidad intrínseca de la nueva célula y de la respectividad extrínseca de ésta con distintos medios en sus sucesivas fases. Con palabras especialmente significativas en el lenguaje matemático podemos decir con absoluta precisión que la fusión singámica no sólo es condición necesaria para la generación de un nuevo ser humano, sino que, precisamente por ello, desde una perspectiva ética es también condición suficiente para que sea considerado como ser humano, en tanto que inicio de un camino único e irreversible.

Su claro sentido, como científico y como creyente, de que la fusión de los dos gametos crea un nuevo individuo con un genoma derivado de ambos progenitores, que es ser humano, PERSONA, en tanto que ser individual, irrepetible, criatura de Dios. La fecundación constituye, pues, condición necesaria y suficiente para saber que ha emergido un nuevo ser humano.

9. Así cantó a la vida, en solicitud de reconocimiento del derecho a la vida, con su compromiso con la defensa de este derecho a la vida desde la germinación del nuevo ser, acontecimiento que consideró expresión inequívoca de una auténtica vida humana. Con este tema por bandera recibió los doctorados honoris causa por las Universidades Católica de Murcia y Pontificia de Salamanca. Y siempre en relación con el Dr. Pedro Guillén, aquí su padrino, y requiriendo afectuosamente mi presencia en ambos actos, en los que tanto disfruté con la honra que se ofrecía al tutor y amigo.

10. Defensa de la vida desde su concepción hasta la muerte natural. Nunca pudo aceptar el considerado 'derecho' al aborto. Para Jiménez Collado, como para mí, no tienen fundamento científico ni ético las consideraciones que se utilizan para justificar la destrucción de los embriones en sus primeras fases bajo otras consideraciones ajenas mediante uso de lenguaje y derechos. Sé cuánto hubiera disfrutado el doctor Juan Jiménez Collado si le hubiera podido manifestar, al modo como comentamos en ocasiones precedentes, que el Papa Francisco en su reciente encíclica Fratelli Tutti, Pontífice tan vilipendiado por el tradicionalismo católico y encíclica tan ninguneada por éste, había expresado su defensa radical de la vida. Esta tercera encíclica de Francisco está siendo considerada como escrita con la finalidad de contribuir a 
la Agenda Globalista o Nuevo Orden Mundial. Pues bien, aunque en medida apreciable esta interpretación se presenta como harto plausible, Francisco se muestra inflexible en ella, en el tema objeto de nuestra atención, cuando trata sobre el 'descarte mundial' ( $\left.n^{\circ} 18\right)$ al escribir: "Partes de la humanidad parecen sacrificables en beneficio de una selección que favorece a un sector digno de vivir sin límites. En el fondo 'no se considera ya a las personas como un valor primario que hay que respetar y amparar, especialmente si son pobres o discapacitadas, si 'todavía no son útiles' -como los no nacidos-, o si 'ya no sirven' -como los ancianos". Para continuar poco más adelante "objeto de descarte no es sólo el alimento o los bienes superfluos, sino con frecuencia los mismos seres humanos" ( $\left.\mathrm{n}^{\circ} 19\right)$.

11. El último año de su vida, el Profesor Jiménez Collado, con un deficiente estado de su salud y creciente deterioro, lo dedicó intensa, casi exclusivamente, a la elaboración del Discurso de Contestación al de Ingreso de nuestro compañero Pedro Guillén. ¡Cuántas horas pasamos juntos en torno a la que sería su última intervención en la Academia! ¡Con cuánta ilusión preparó dicho Discurso de Contestación!

12. Mi reconocimiento, pues, y gratitud, inmensa, por tantos servicios y tan grata y estimulante conducta, al considerado por el Dr. Guillén en su extraordinaria Necrológica "leal, muy exigente y sincero" Profesor Juan Jiménez Collado, nuestro compañero, al que hoy honramos con esta despedida académica. Que descanse en paz.

\section{DECLARACIÓN DE TRANSPARENCIA}

El autor/a de este artículo declara no tener ningún tipo de conflicto de intereses respecto a lo expuesto en el presente trabajo. 